Article

\title{
Biocatalytic Synthesis of Poly $(\delta$-Valerolactone) Using a Thermophilic Esterase from Archaeoglobus fulgidus as Catalyst
}

\section{Hong Cao ${ }^{1,2, \dagger}$, Haobo Han ${ }^{1, \dagger}$, Guangquan $\mathrm{Li}^{2}$, Jiebing Yang ${ }^{1}$, Lingfei Zhang ${ }^{1}$, Yan Yang ${ }^{1, *}$, Xuedong Fang ${ }^{2, *}$ and Quanshun $\mathrm{Li}^{1, *}$}

1 Key Laboratory for Molecular Enzymology and Engineering of Ministry of Education, College of Life Science, Jilin University, Changchun 130012, China;

E-Mails: caohong1967@163.com (H.C.); hanhb1310@mails.jlu.edu.cn (H.H.); yangjiebing920320@yahoo.cn (J.Y.); fairy34100326@yahoo.cn (L.Z.)

2 Department of General Surgery, Second Hospital, Jilin University, Changchun 130041, China; E-Mail: guangquanli83@gmail.com

$\dagger$ These authors contributed equally to this work.

* Authors to whom correspondence should be addressed; E-Mails: yyan@jlu.edu.cn (Y.Y.); fangxuedong@medmail.com.cn (X.F.); quanshun@jlu.edu.cn (Q.L.); Tel.: +86-431-8515-5216 (Q.L.); Fax: +86-431-8515-5200 (Q.L.).

Received: 26 July 2012; in revised form: 24 August 2012 / Accepted: 7 September 2012 / Published: 25 September 2012

\begin{abstract}
The ring-opening polymerization of $\delta$-valerolactone catalyzed by a thermophilic esterase from the archaeon Archaeoglobus fulgidus was successfully conducted in organic solvents. The effects of enzyme concentration, temperature, reaction time and reaction medium on monomer conversion and product molecular weight were systematically evaluated. Through the optimization of reaction conditions, poly( $\delta$-valerolactone $)$ was produced in $97 \%$ monomer conversion, with a number-average molecular weight of $2225 \mathrm{~g} / \mathrm{mol}$, in toluene at $70{ }^{\circ} \mathrm{C}$ for $72 \mathrm{~h}$. This paper has produced a new biocatalyst for the synthesis of poly( $\delta$-valerolactone), and also deeper insight has been gained into the mechanism of thermophilic esterase-catalyzed ring-opening polymerization.
\end{abstract}

Keywords: thermophilic esterase; ring-opening polymerization; $\delta$-valerolactone 


\section{Introduction}

$\operatorname{Poly}(\delta$-valerolactone) (PVL) is an important aliphatic polyester due to its good biodegradability, biocompatibility, and permeability characteristics. Thus, it can be used as a hydrophobic block in amphiphilic block copolymers, which are suitable for constructing micellar delivery systems of hydrophobic antitumor drugs [1]. At present, PVL is mainly synthesized using organometallic catalysts, e.g., aluminium alkoxides, tin carboxylates and phosphido-diphosphine Group 3 complexes [2,3]. However, the trace metallic residues are not tolerated in biomedical applications due to their toxicity. In the past two decades, enzymatic ring-opening polymerization has been extensively developed [4-9], and has potential as a powerful route for synthesizing metal-free PVL or its copolymers under mild reaction conditions.

Compared with $\varepsilon$-caprolactone (the most widely investigated monomer), $\delta$-valerolactone has attracted less attention in enzymatic ring-opening polymerization, mainly due to its relatively lower activity. Through the optimization of reaction conditions (enzyme origin, temperature, reaction medium and time), PVL was successfully synthesized in a biocatalytic route, with the highest monomer conversion and number-average molecular weight $\left(M_{\mathrm{n}}\right)$ of $98 \%$ and $3200 \mathrm{~g} / \mathrm{mol}$, respectively [10]. Using ionic liquids as reaction medium, the ring-opening polymerization of $\delta$-valerolactone with Candida antarctica lipase B (CALB) could also be realized, producing a product with a degree of polymerization of only 25 [11]. Similar to these results, previous work in our laboratory showed that a recombinant Escherichia coli whole-cell biocatalyst harboring the thermophilic lipase gene FN1333 could efficiently catalyze the ring-opening polymerization of $\delta$-valerolactone, with monomer conversion of $97 \%$ and product $M_{\mathrm{n}}$ value of $1020 \mathrm{~g} / \mathrm{mol}$ at $70{ }^{\circ} \mathrm{C}$ in toluene [12]. Michaelis-Menten kinetic analysis elucidated that due to the $c$ is conformation of the ester bond of $\delta$-valerolactone, CALB exhibited a similar affinity $\left(K_{\mathrm{m}}=0.73 \mathrm{~mol} / \mathrm{L}\right)$ to $\varepsilon$-caprolactone $\left(K_{\mathrm{m}}=0.72 \mathrm{~mol} / \mathrm{L}\right)$; nevertheless, the $k_{\text {cat }}$ value for the CALB-catalyzed ring-opening polymerization of $\delta$-valerolactone $\left(k_{\text {cat }}=35.2 \mathrm{~s}^{-1}\right)$ was obviously lower than that of $\varepsilon$-caprolactone $\left(k_{\mathrm{cat}}=72.9 \mathrm{~s}^{-1}\right)$ [13-15]. Meanwhile, the monomer $\delta$-valerolactone showed a much higher hydrolysis rate, almost 21-fold higher than $\varepsilon$-caprolactone [13], which was unfavorable for the enzymatic ring-opening polymerization. Thus, the monomer $\delta$-valerolactone has relatively lower activity in enzymatic polymerization than $\varepsilon$-caprolactone, and is hard to polymerize enzymatically in a high yield with the product molecular weight. Potential strategies to solve this problem are to explore novel enzymes with high catalytic activity and stability from extremophiles, or to construct tailor-made biocatalysts via protein engineering techniques.

Thermophilic esterase from the hyperthermophilic archaeon Archaeoglobus fulgidus (AFEST) has been cloned, over-expressed in E. coli and well characterized with respect to substrate specificity, crystal structure and catalytic mechanism [16-19]. The enzyme was classified as a member of a hormone-sensitive lipase group of the esterase/lipase family, with an optimal temperature of $80{ }^{\circ} \mathrm{C}[17,18]$. It could catalyze the hydrolysis of a broad range of esters, including $p$-nitrophenyl esters, vinyl esters, and triacylglycerols with a short chain, and it exhibited the highest activity towards $p$-nitrophenyl hexanoate among the $p$-nitrophenyl esters tested [17]. Previous work in our laboratory demonstrated that it could successfully catalyze the ring-opening polymerization of $\varepsilon$-caprolactone, with $100 \%$ monomer conversion and product $M_{\mathrm{n}}$ of $1400 \mathrm{~g} / \mathrm{mol}$ in toluene at $80{ }^{\circ} \mathrm{C}$ for $48 \mathrm{~h}[20,21]$. 
In the present study, ring-opening polymerization of $\delta$-valerolactone was conducted using the thermophilic esterase AFEST as catalyst. Systematical optimization of the reaction conditions was performed to obtain high monomer conversion and product molecular weight, and thus was helpful for gaining deeper insight into the mechanism underlying the effects of the reaction conditions.

\section{Results and Discussion}

\subsection{Purification of the Recombinant Enzyme AFEST}

The recombinant E. coli BL21 strain was first cultured and the cells were harvested through centrifugation. Afterwards, through ultrasonic cell disintegration and unique thermal precipitation strategy [22], the recombinant enzyme AFEST was considerably purified. Finally, ultrafiltration and lyophilization were employed to remove the fractions of low molecular weight and obtain the enzyme preparation, respectively. The SDS-PAGE analysis showed a major band at $35.5 \mathrm{kDa}$, which corresponded to the enzyme AFEST, and the purity was more than $92 \%$ (Figure 1). The lyophilized AFEST, with a specific activity of $168 \mathrm{U} / \mathrm{mg}$ towards $p$-nitrophenyl caprylate at $80{ }^{\circ} \mathrm{C}$ [20], was then used as catalyst in the ring-opening polymerization of $\delta$-valerolactone.

Figure 1. SDS-PAGE analysis of the recombinant enzyme AFEST. Lane 1: protein marker; Lane 2: the purified recombinant enzyme AFEST. Protein standards employed were: rabbit phosphorylase $\mathrm{b}(97 \mathrm{kDa})$, bovine serum albumin $(66 \mathrm{kDa})$, rabbit actin $(43 \mathrm{kDa})$, bovine carbonic anhydrase $(31 \mathrm{kDa})$, and trypsin inhibitor $(20 \mathrm{kDa})$.

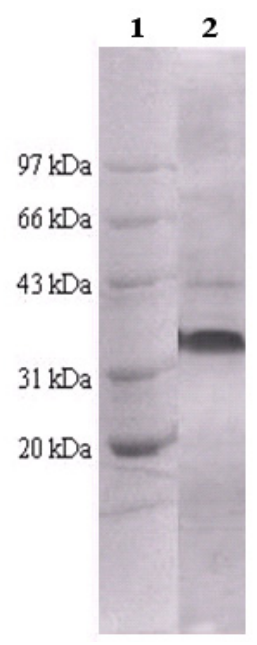

The ring-opening polymerization of $\delta$-valerolactone was first performed using $30 \mathrm{mg}$ AFEST in toluene at $70{ }^{\circ} \mathrm{C}$ for $72 \mathrm{~h}$, and the product obtained was characterized by ${ }^{1} \mathrm{H}$ NMR. As shown in Figure 2, the spectrum confirmed the structure of PVL as follows: 1.68 (m, $-\mathrm{COCH}_{2} \mathrm{CH}_{2} \mathrm{CH}_{2} \mathrm{CH}_{2} \mathrm{O}-$ ), $2.35\left(\mathrm{t},-\mathrm{COCH}_{2}-\right), 3.64\left(\mathrm{t},-\mathrm{CH}_{2} \mathrm{OH}\right.$ end group), $4.09\left(\mathrm{t},-\mathrm{CH}_{2} \mathrm{O}-\right)$. Through the calculation of peak areas at 3.64 and $4.09 \mathrm{ppm}\left(\left(\mathrm{Area}_{4.09} / \mathrm{Area}_{3.64}+1\right) \times 100\right)$, the $M_{\mathrm{n}}$ value of the product was ca. $1540 \mathrm{~g} / \mathrm{mol}$. Compared with the conventional chemical route (e.g., PVL with molecular weight of 21,200 g/mol was obtained using phosphido-diphosphine Group 3 complexes [3]), the synthesized polymers in the present research are of low molecular weight, and might be used as the soft segments in thermoplastic elastomers, or carriers for controlled drug delivery and release. 
Figure 2. ${ }^{1} \mathrm{H}$ NMR spectrum of the product synthesized by AFEST-catalyzed ring-opening polymerization of $\delta$-valerolactone in toluene at $70{ }^{\circ} \mathrm{C}$ for $72 \mathrm{~h}$.

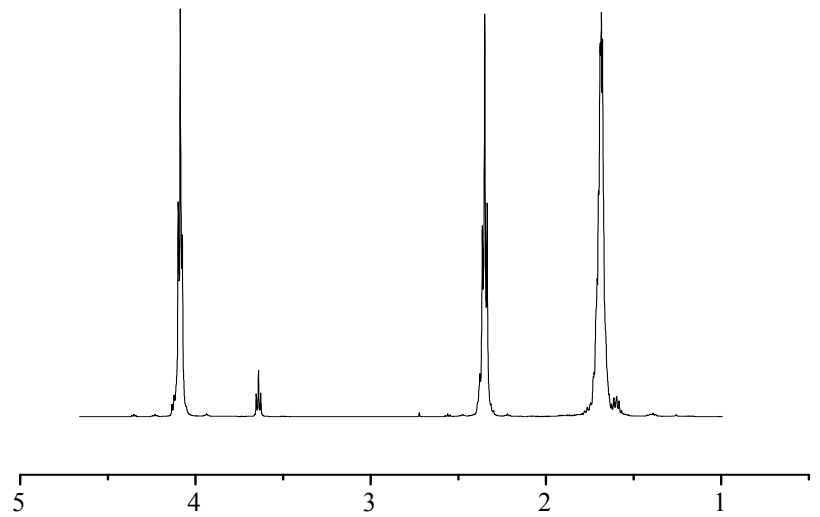

\subsection{Effect of Enzyme Concentration}

In the lipase-catalyzed polyester synthesis, enzyme concentration played an important role in both monomer conversion and product molecular weight [23]. The effect of enzyme concentration was investigated using different amounts of enzyme AFEST, $200 \mu \mathrm{L} \delta$-valerolactone and $600 \mu \mathrm{L}$ toluene at $80{ }^{\circ} \mathrm{C}$ for $72 \mathrm{~h}$. Monomer conversion and $M_{\mathrm{n}}$ as a function of the amount of enzyme are shown in Figure 3. Obviously, increasing the enzyme concentration should be favorable for increasing monomer conversion, and when the amount of enzyme exceeded $30 \mathrm{mg}$, the monomers were completely converted ( $>97 \%$ monomer conversion). Similar to monomer conversion, $M_{\mathrm{n}}$ values also exhibited a tendency to increase at relatively low amounts of enzyme $(<30 \mathrm{mg})$, and at large amounts of enzyme (>30 mg), $M_{\mathrm{n}}$ values remained constant (1490-1650 g/mol). However, in the AFEST-catalyzed ring-opening polymerization of $\varepsilon$-caprolatone, $M_{\mathrm{n}}$ values were almost independent of the monomer conversions, and remained constant in the range of 30-100 mg amount of enzyme [20]. This phenomenon was probably caused by the fact that large amounts of insoluble enzyme in the reaction system could lead to mass transfer limitation, and thus in the subsequent research, $30 \mathrm{mg}$ AFEST was selected as the optimal amount of enzyme.

Figure 3. Monomer conversion ( $\mathbf{a})$ and $M_{\mathrm{n}}(\boldsymbol{\Delta})$ as a function of amount of enzyme for AFEST-catalyzed ring-opening polymerization of $\delta$-valerolactone. The reactions were conducted in toluene at $80{ }^{\circ} \mathrm{C}$ for $72 \mathrm{~h}$.

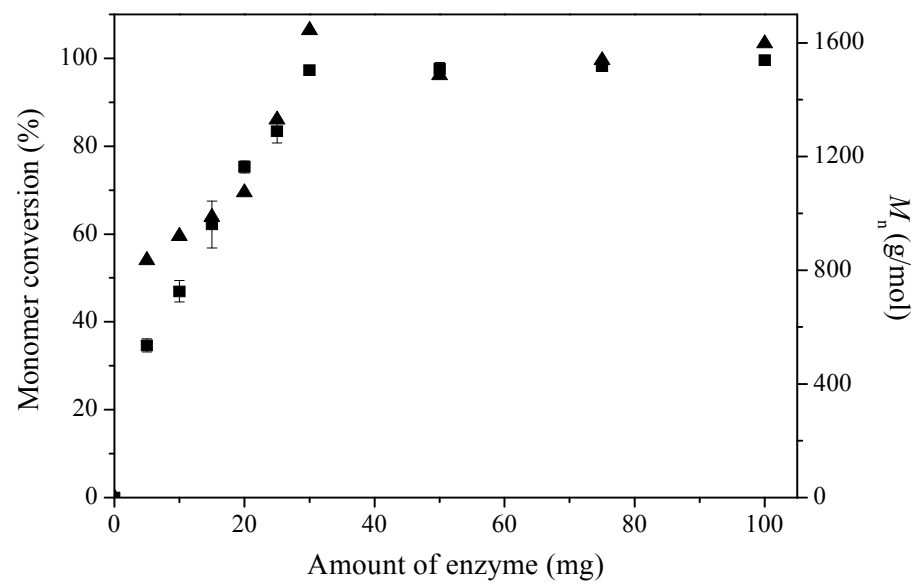




\subsection{Effect of Temperature}

Effect of temperature on monomer conversion and product molecular weight was investigated at different temperatures in toluene for $72 \mathrm{~h}$. As shown in Figure 4, high monomer conversions were achieved at high temperatures, and in the range of $70-90{ }^{\circ} \mathrm{C}$, the monomers were almost completely consumed, with monomer conversion values of higher than $97 \%$. For the product $M_{\mathrm{n}}$ values, reaction at $70{ }^{\circ} \mathrm{C}$ exhibited the highest value of $2225 \mathrm{~g} / \mathrm{mol}$, which was higher than that calculated through ${ }^{1} \mathrm{H}$ NMR (1540 g/mol) as described above. In the AFEST-catalyzed poly( $\varepsilon$-caprolatone) synthesis [20], high temperature was favorable for the product molecular weight; and thus the results in the present study are different, but it is a common phenomenon, mainly due to the different binding affinity of AFEST towards different monomers. With regard to monomer conversion and $M_{\mathrm{n}}$ values, $70{ }^{\circ} \mathrm{C}$ was employed as the optimal reaction temperature.

Figure 4. Effect of temperature on monomer conversion and product molecular weight $M_{\mathrm{n}}$. The reactions were carried out using $200 \mu \mathrm{L} \delta$-valerolactone and $600 \mu \mathrm{L}$ toluene at different temperatures in toluene for $72 \mathrm{~h}$.

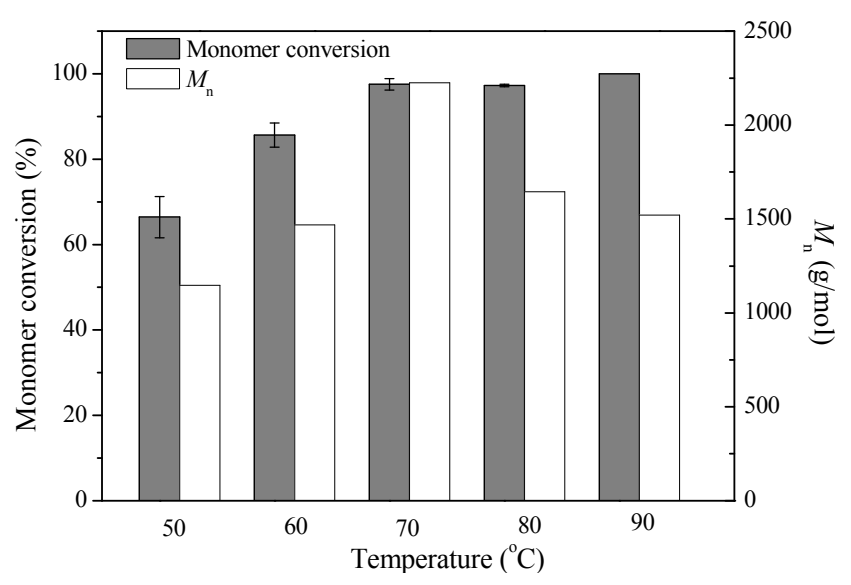

\subsection{Effect of Reaction Time}

Time-course studies of AFEST-catalyzed ring-opening polymerization of $\delta$-valerolactone were performed in toluene at $70{ }^{\circ} \mathrm{C}$ for different reaction times. Figure 5 shows the corresponding plots of monomer conversion and $M_{\mathrm{n}}$ vs. reaction time. During the polymerization before $72 \mathrm{~h}$, the monomer conversion and $M_{\mathrm{n}}$ increased with reaction time. After $72 \mathrm{~h}$, monomer conversion values could still increase from $97 \%\left(72 \mathrm{~h}\right.$ ) to $100 \%$ (96 and $120 \mathrm{~h}$ ). However, the $M_{\mathrm{n}}$ values exhibited an obvious tendency to decrease after $72 \mathrm{~h}$. In enzymatic ring-opening polymerization, enzymatic hydrolysis and transesterification are also involved in the reaction system [24], and thus we can conclude that before $72 \mathrm{~h}$, rapid chain initiation and propagation could lead to the increasing monomer conversion and $M_{\mathrm{n}}$ values, and after $72 \mathrm{~h}$, hydrolysis and transesterification of the formed polyester chains play important roles in the reaction system, which is probably the main reason for the decreasing $M_{\mathrm{n}}$ values. Interestingly, higher PDI values were also obtained in hydrophobic solvents. In addition to catalyzing polymerization, lipases and esterases can also cleave the ester bonds of polyesters, thus catalyzing the degradation, inter-transesterification and intra-transesterification of the polymer chain [24]. The use of hydrophobic solvents results in an improved degree of polymerization, but might also lead to increased 
rates of hydrolysis and transesterification; this in turn results in a polymer with a broader molecular weight distribution.

Figure 5. Monomer conversion ( $\boldsymbol{\square})$ and $M_{\mathrm{n}}(\boldsymbol{\Delta})$ as a function of reaction time for AFEST-catalyzed ring-opening polymerization of $\delta$-valerolactone. The reactions were conducted in toluene at $70{ }^{\circ} \mathrm{C}$ for different reaction times.

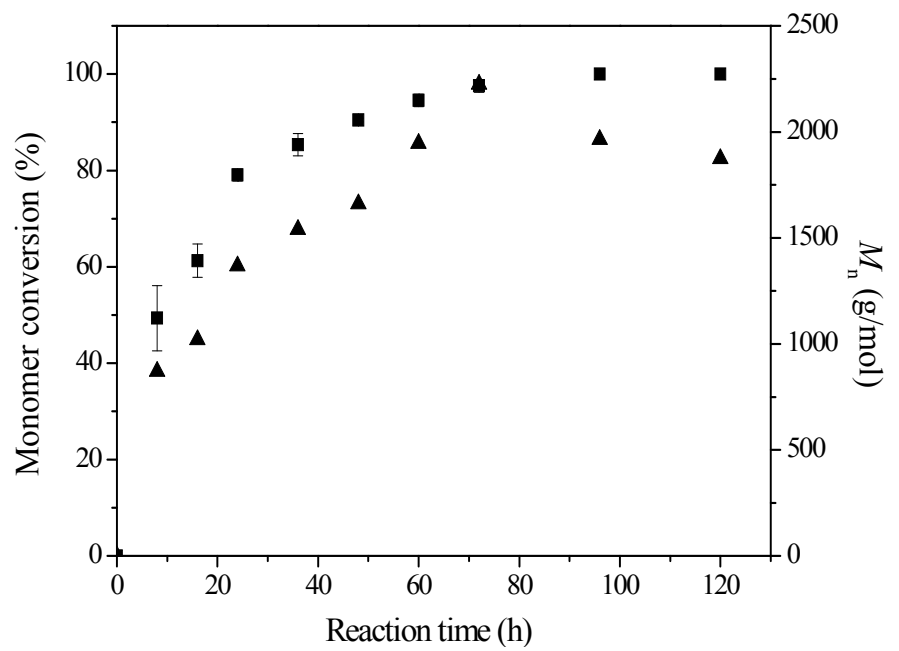

\subsection{Effect of Reaction Medium}

The nature of solvents employed plays a crucial role in determining the stability of the biocatalyst and in the partitioning of substrates and products between the solvent and the biocatalyst in non-aqueous biocatalytic systems [25]. The effect of organic solvents with different $\log P$ values on monomer conversion and $M_{\mathrm{n}}$ at $70{ }^{\circ} \mathrm{C}$ for $72 \mathrm{~h}$ is summarized in Table 1 ( $\log P$ is the octanol/water partition coefficient value [26]). Similar to AFEST-catalyzed ring-opening polymerization of $\varepsilon$-caprolactone [20], high monomer conversion ( $>97 \%)$ and $M_{\mathrm{n}}$ values $(1860-2225 \mathrm{~g} / \mathrm{mol})$ were achieved in hydrophobic solvents (toluene, cyclohexane and n-hexane), which could be ascribed to the deactivation of enzyme by the relatively hydrophilic solvents, since these solvents might disrupt the functional structure or strip off the essential water layer from the enzyme [27,28]. In addition, enzymatic ring-opening polymerization of $\delta$-valerolatone could also proceed in a solvent-free system, with monomer conversion and $M_{\mathrm{n}}$ values of $94 \%$ and $1620 \mathrm{~g} / \mathrm{mol}$, respectively. In all, toluene was selected as the optimal reaction medium in the present research.

Table 1. Effects of organic solvents on monomer conversion and product molecular weight $M_{\mathrm{n}}$. The reactions were conducted using $200 \mu \mathrm{L} \delta$-valerolactone and $600 \mu \mathrm{L}$ toluene at $70{ }^{\circ} \mathrm{C}$ for $72 \mathrm{~h}$ in different organic solvents.

\begin{tabular}{ccccc}
\hline Solvent & Log $\boldsymbol{P}$ & Monomer conversion $\mathbf{( \% )}$ & $\boldsymbol{M}_{\mathbf{n}} \mathbf{( g / \mathbf { m o l } )}$ & $\mathbf{P D I}$ \\
\hline 1,4-Dioxane & -1.10 & 86 & 860 & 1.09 \\
Acetone & -0.23 & 87 & 850 & 1.12 \\
Tetrahydrofuran & 0.49 & 93 & 910 & 1.10 \\
Dichloromethane & 0.93 & 72 & 860 & 1.14 \\
Chloroform & 2.00 & 91 & 960 & 1.15 \\
Toluene & 2.50 & 97 & 2225 & 1.37 \\
\hline
\end{tabular}


Table 1. Cont.

\begin{tabular}{ccccc}
\hline Solvent & $\log \boldsymbol{P}$ & Monomer conversion $\mathbf{( \% )}$ & $\boldsymbol{M}_{\mathbf{n}}(\mathbf{g} / \mathbf{m o l})$ & PDI \\
\hline Cyclohexane & 3.09 & 100 & 1860 & 1.28 \\
n-Hexane & 3.50 & 100 & 1970 & 1.29 \\
Solvent-free & - & 94 & 1620 & 1.26 \\
\hline
\end{tabular}

\section{Experimental Section}

\subsection{Materials}

Recombinant E. coli BL21 harboring the thermophilic esterase gene AF1716 from A. fulgidus was kindly provided by Dr. Giuseppe Manco (Istituto di Biochimica delle Proteine, Italy). Yeast extract and tryptone was purchased from Oxoid Ltd (Basingstoke, UK). Isopropyl $\beta$-D-thiogalactopyranoside (IPTG), ampicillin and $p$-nitrophenyl caprylate were purchased from Sigma (Shanghai, China). $\delta$-Valerolactone was purchased from Sigma (Shanghai, China) in the highest available purity and used as received. Molecular sieves ( $4 \AA$ ) were purchased from Tianjin Chemical Co. (Tianjin, China), and heated at $500{ }^{\circ} \mathrm{C}$ for $3 \mathrm{~h}$. Organic solvents of analytical grade were purchased from Beijing Chemical Co. (Beijing, China), and dried over $4 \AA$ molecular sieves before use. All other reagents were of the highest reagent grade commercially available, and used without further purification.

\subsection{Purification of the Recombinant Enzyme AFEST}

The recombinant $E$. coli BL21 strain was cultured in 2 YT medium (1\% yeast extract, $1.6 \%$ tryptone, and $0.5 \% \mathrm{NaCl})$ containing ampicillin $(100 \mu \mathrm{g} / \mathrm{mL})$ at $37{ }^{\circ} \mathrm{C}$. When the optical density at $600 \mathrm{~nm}$ of the culture reached a value of 1.8 , the induction was performed by adding IPTG at a final concentration of $1 \mathrm{mM}$ and shaking for an additional $3 \mathrm{~h}$ at $37{ }^{\circ} \mathrm{C}$. The cells were harvested by centrifugation at $8000 \mathrm{rpm}$ for $15 \mathrm{~min}$, and washed with $50 \mathrm{mM}$ phosphate buffer (pH 8.0). The harvested cells were frozen and thawed three times, and then suspended in $50 \mathrm{mM}$ phosphate buffer $\left(\mathrm{pH} \mathrm{8.0)}\right.$ at a ratio of 1:6 (w/v). After ultrasonic cell disintegration and incubation at $80{ }^{\circ} \mathrm{C}$ for $30 \mathrm{~min}$, the suspension was then centrifuged at $8000 \mathrm{rpm}$ for $15 \mathrm{~min}$. The solution was collected, ultrafiltrated under a $10 \mathrm{kDa}$ membrane and lyophilized to obtain the enzyme preparation.

The esterase activity was monitored by measuring the amount of $p$-nitrophenyl from the hydrolysis of $p$-nitrophenyl caprylate at $80{ }^{\circ} \mathrm{C}$ [29]. One unit of enzymatic activity was defined as the amount of protein releasing $1 \mu \mathrm{mol} p$-nitrophenyl from $p$-nitrophenyl caprylate in one minute.

\subsection{Enzymatic Ring-Opening Polymerization of $\delta$-Valerolactone}

The thermophilic esterase AFEST was dried in a desiccator overnight, and then transferred to a dried screw-capped vial containing $200 \mu \mathrm{L} \delta$-valerolactone and $600 \mu \mathrm{L}$ organic solvent (no solvent addition for solvent-free system). Ethylbenzene $(50 \mu \mathrm{L})$ was added as an internal standard for the quantification of monomer conversion by gas chromatography (GC). The vial was sealed and then placed into a thermostatic reactor with stirring $(180 \mathrm{rpm})$ at the appropriate temperature. After the reaction, $5 \mathrm{~mL}$ dichloromethane was added, and the enzyme was removed by filtration. The enzyme was washed three times with dichloromethane, and the filtrate was collected and evaporated under 
reduced pressure to remove dichloromethane. Afterwards, the viscous sample was precipitated in methanol at $-20{ }^{\circ} \mathrm{C}$, and the cloudy solution was centrifuged $\left(8000 \mathrm{rpm}, 15 \mathrm{~min}, 4{ }^{\circ} \mathrm{C}\right)$. The white precipitate was then collected, dried in a vacuum oven, and then characterized by ${ }^{1} \mathrm{H}$ NMR.

\subsection{Structural Characterization of PVL}

The structure of the polymer was characterized by ${ }^{1} \mathrm{H}$ NMR. The ${ }^{1} \mathrm{H}$ NMR spectrum was recorded in chloroform-d $\left(\mathrm{CDCl}_{3}\right)$ on an AVANCE DMX 500 spectrometer at $500 \mathrm{MHz}$. The chemical shifts for ${ }^{1} \mathrm{H}$ NMR spectra were referenced relative to tetramethylsilane (TMS, $0.00 \mathrm{ppm}$ ).

\subsection{Determination of Monomer Conversion}

Monomer conversion values were determined by GC using a Shimadzu 2014 gas chromatograph (Shanghai, China) equipped with an Rtx-1 capillary column $(30 \mathrm{~m} \times 0.25 \mathrm{~mm} \times 0.25 \mu \mathrm{m})$ and a hydrogen flame ionization detector. Nitrogen was used as the carrier gas. The temperatures of injection pool and detector were set as $200{ }^{\circ} \mathrm{C}$ and $240{ }^{\circ} \mathrm{C}$, respectively. The column temperature was held at $70{ }^{\circ} \mathrm{C}$ for $2 \mathrm{~min}$, and then programmed to rise at $10^{\circ} \mathrm{C} / \mathrm{min}$ to a final temperature of $140{ }^{\circ} \mathrm{C}$, which was then maintained for $2 \mathrm{~min}$. The injection volume was $1.0 \mu \mathrm{L}$.

\subsection{Determination of Molecular Weight and Polydispersity Index (PDI)}

The $M_{\mathrm{n}}$, weight-average molecular weight $\left(M_{\mathrm{w}}\right)$ and PDI $\left(M_{\mathrm{w}} / M_{\mathrm{n}}\right)$ values of products were determined by gel permeation chromatography (GPC). Analyses were carried out using a Shimadzu HPLC system (Shanghai, China) equipped with a refractive index detector and Shim-pack GPC-804 and GPC-8025 ultrastyragel columns in series. Tetrahydrofuran was used as the eluent with a flow rate of $1.0 \mathrm{~mL} / \mathrm{min}$ at $40{ }^{\circ} \mathrm{C}$. The sample concentration and injection volume were $0.3 \%(w / v)$ and $20 \mu \mathrm{L}$, respectively. The GPC system was calibrated with polystyrene standards of narrow molecular weight distribution.

\section{Conclusions}

In this paper, PVL was successfully synthesized using a thermophilic esterase AFEST from the archaeon $A$. fulgidus as catalyst. The synthesized PVL was of low molecular weight and narrow molecular weight distribution, and is expected to be widely used as the soft block of thermoplastic elastomers, or carriers for controlled drug delivery and release. This work provided a new green and sustainable route for polyester synthesis, and was also helpful in broadening the application scope of thermophilic esterases and facilitating insight into the mechanism of thermophilic esterase-catalyzed ring-opening polymerization.

\section{Acknowledgments}

This work was supported by the Natural Science Foundation of China (No. 21204025, 21074042 and 81102383), the Ministry of Science and Technology of China (International Cooperation and Communication Program 2011DFR51090), Doctoral Fund of Young Scholars of the Ministry of Education (No. 20110061120028), the China Postdoctoral Science Foundation (No. 20110491328 and 
2012T50311), and the grant from Jilin Province Science \& Technology in China (No. 201101040) and Development and Reform Commission of Jilin University (No. JF2012C007-3).

\section{References}

1. Nair, L.K.; Jagadeeshan, S.; Nair, S.A.; Kumar, G.S.V. Evaluation of triblock copolymeric micelles of $\delta$-valerolactone and poly (ethylene glycol) as a competent vector for doxorubicin delivery against cancer. J. Nanobiotechnol. 2011, 9, 42.

2. Vaida, C.; Takwa, M.; Martinelle, M.; Hult, K.; Keul, H.; Moller, M. $\gamma$-Acyloxy-e-caprolatone: Synthesis, ring-opening polymerization vs. rearrangement by means of chemical and enzymatic catalysis. Macromol. Symp. 2008, 272, 28.

3. D’Auria, I.; Mazzeo, M.; Pappalardo, D.; Lamberti, M.; Pellecchia, C. Ring-opening polymerization of cyclic esters promoted by phosphido-diphosphine pincer group 3 complexes. J. Polym. Sci. A: Polym. Chem. 2011, 49, 403-413.

4. Varma, I.K.; Albertsson, A.C.; Rajkhowa, R.; Srivastava, R.K. Enzyme catalyzed synthesis of polyesters. Prog. Polym. Sci. 2005, 30, 949-981.

5. Kobayashi, S.; Makino, A. Enzymatic polymer synthesis: An opportunity for green polymer chemistry. Chem. Rev. 2009, 109, 5288-5353.

6. Kobayashi, S. Recent developments in lipase-catalyzed synthesis of polyesters. Macromol. Rapid Commun. 2009, 30, 237-266.

7. Kobayashi, S. Lipase-catalyzed polyester synthesis: A green polymer chemistry. Proc. Jpn. Acad. Ser. B 2010, 86, 338-365.

8. Kadokawa, J.; Kobayashi, S. Polymer synthesis by enzymatic catalysis. Curr. Opin. Chem. Biol. 2010, 14, 145-153.

9. Yang, Y.; Yu, Y.; Zhang, Y.; Liu, C.; Shi, W.; Li, Q. Lipase/esterase-catalyzed ring-opening polymerization: A green polyester synthesis technique. Process Biochem. 2011, 46, 1900-1908.

10. Kobayashi, S.; Takeya, K.; Suda, S.; Uyama, H. Lipase-catalyzed ring-opening polymerization of medium-size lactones to polyesters. Macromol. Chem. Phys. 1998, 199, 1729-1736.

11. Gorke, J.T.; Okrasa, K.; Louwagie, A.; Kazlauskas, R.J.; Srienc, F. Enzymatic synthesis of poly(hydroxyalkanoates) in ionic liquids. J. Biotechnol. 2007, 132, 306-313.

12. Li, Q.; Li, G.; Ma, F.; Zhang, Z.; Zheng, B.; Feng, Y. Highly efficient ring-opening polymerization of $\varepsilon$-capaolactone catalyzed by a recombinant Escherichia coli whole-cell biocatalyst. Process Biochem. 2011, 46, 477-481.

13. Van der Mee, L.; Helmich, F.; de Bruijn, R.; Vekemans, J.A.J.M.; Palmans, A.R.A.; Meijer, E.W. Investigation of lipase-catalyzed ring-opening polymerizations of lactones with various ring sizes: Kinetic evaluation. Macromolecules 2006, 39, 5021-5027.

14. Van Buijtenen, J.; van As, B.A.C.; Verbruggen, M.; Roumen, L.; Vekemans, J.A.J.M.; Pieterse, K.; Hilbers, P.A.J.; Hulshof, L.A.; Palmans, A.R.A.; Meijer, E.W. Switching from $S$ - to $R$-selectivity in the Candida antarctica lipase B-catalyzed ring-opening of $\omega$-methylated lactones: Tuning polymerizations by ring size. J. Am. Chem. Soc. 2007, 129, 7393-7398.

15. Veld, M.A.J.; Fransson, L.; Palmans, A.R.A.; Meijer, E.W.; Hult, K. Lactone size dependent reactivity in Candida antarctica lipase B: Molecular dynamics and docking study. ChemBioChem 2009, 10, 1330-1334. 
16. D’Auria, S.; Herman, P.; Lakowicz, J.R.; Bertoli, E.; Tanfani, F.; Rossi, M.; Manco, G. The thermophilic esterase from Archaeoglobus fulgidus: Structure and conformational dynamics at high temperature. Proteins 2000, 38, 351-360.

17. Manco, G.; Giosue, E.; D’Auria, S.; Herman, P.; Carrea, G.; Rossi, M. Cloning, overexpression, and properties of a new thermophilic and thermostable esterase with sequence similarity to hormone-sensitive lipase subfamily from the archaeon Archaeoglobus fulgidus. Arch. Biochem. Biophys. 2000, 373, 182-192.

18. Simone, G.D.; Menchise, V.; Manco, G.; Mandrich, L.; Sorrentino, N.; Lang, D.; Rossi, M.; Pedone, C. The crystal structure of a hyper-thermophilic carboxylesterase from the archaeon Archaeoglobus fulgidus. J. Mol. Biol. 2001, 314, 507-518.

19. Chaninian, H.; Ali, Y.B.; Abousalham, A.; Petry, S.; Mandrich, L.; Manco, G.; Canaan, S.; Sarda, L. Substrate specificity and kinetic properties of enzymes belonging to the hormone-sensitive lipase family: Comparison with non-lipolytic and lipolytic carboxylesterases. Biochim. Biophys. Acta 2005, 1738, 29-36.

20. Ma, J.; Li, Q.; Song, B.; Liu, D.; Zheng, B.; Zhang, Z.; Feng, Y. Ring-opening polymerization of $\varepsilon$-caprolactone catalyzed by a novel thermophilic esterase from the archaeon Archaeoglobus fulgidus. J. Mol. Catal. B: Enzym. 2009, 56, 151-157.

21. Li, G.; Li, Q. Thermophilic esterase from the archaeon Archaeoglobus fulgidus physically immobilized on hydrophobic macroporous resin: A novel biocatalyst for polyester synthesis. Biotechnol. Bioprocess E. 2011, 16, 1201-1207.

22. Ren, X.; Yu, D.; Yu, L.; Gao, G.; Han, S.; Feng, Y. A new study of cell disruption to release recombinant thermostable enzyme from Escherichia coli by thermolysis. J. Biotechnol. 2007, 129, 668-673.

23. Deng, F.; Gross, R.A. Ring-opening bulk polymerization of $\varepsilon$-caprolactone and trimethylene carbonate catalyzed by lipase Novozym 435. Int. J. Biol. Macromol. 1999, 25, 153-159.

24. Sivalingam, G.; Madras, G. Modeling of lipase catalyzed ring-opening polymerization of E-caprolatone. Biomacromolecules 2004, 5, 603-609.

25. Klibanov, A.M. Improving enzymes by using them in organic solvents. Nature 2001, 409, 241-246.

26. Finding Physical and Chemical Properties. Science and Engineering Library from Vanderbilt University. Available online: http://www.library.vanderbilt.edu/science/chem/property.html\#logp (accessed on 18 September 2012).

27. Dong, H.; Cao, S..; Li, Z..; Han, S.; You, D.; Shen, J. Study on the enzymatic polymerization of mechanism of lactones and the strategy for improving the degree of polymerization. J. Polym. Sci. A: Polym. Chem. 1999, 37, 1265-1275.

28. Chua, L.S.; Sarmidi, M.R. Effect of solvent and initial water content on $(R, S)$-1-phenylethanol resolution. Enzyme Microb. Technol. 2006, 38, 551-556.

29. Gao, R.; Feng, Y.; Ishikawa, K.; Ishida, H.; Ando, S.; Kosugi, Y.; Cao, S. Cloning, purification and properties of a hyperthermophilic esterase from archaeon Aeropyrum pernix K1. J. Mol. Catal. B: Enzym. 2003, 24-25, 1-8.

(C) 2012 by the authors; licensee MDPI, Basel, Switzerland. This article is an open access article distributed under the terms and conditions of the Creative Commons Attribution license (http://creativecommons.org/licenses/by/3.0/). 